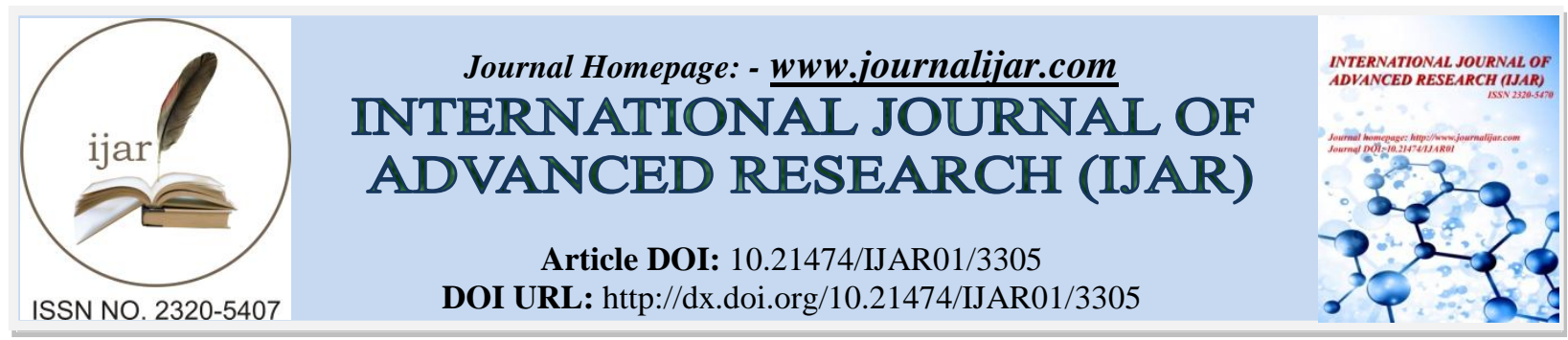

RESEARCH ARTICLE

\title{
THE IMPROVEMENT OF BIOCOMPATIBILITY OF THE DENTAL TITANIUM ALLOY IMPLANTS WITH DLC COATING:IN VITRO AND IN VIVO STUDY.
}

\section{Sidqui $\mathbf{M}^{2}$, Slimani $\mathrm{F}^{1}$, Marzak $\mathrm{J}^{2}$, Hassar $\mathbf{G}^{2}$, Bouzoubaa $\mathbf{M}^{2}$, Chadly $\mathbf{B}^{3}$, Elazhari $\mathbf{M}^{3}$, Dersi $\mathrm{N}^{3}$, Bourjilat FZ $^{3}$, Chekkoury EI Idrissi $A^{1}$ and Aboussaouira $\mathbf{T}^{4}$.}

1. Department of Oral Maxillofacial Surgery, Faculty of Medicine and pharmacy, Casablanca, Morocco.

2. Consultations and Dental Emergency Services, Prosthetic joint, Faculty of Dentistry, Casablanca. Hassan II University of Casablanca. Morocco.

3. Bacteriology and Cytogenetic Services, Pasteur Institute, Casablanca, Morocco.

4. Cell Culture Unit, Centre for Research and Training in Health Sciences, Faculty of Medicine and Pharmacy, Casablanca, Morocco.

\section{Manuscript Info}

Manuscript History

Received: 22 December 2016

Final Accepted: 23 January 2017

Published: February 2017

Key words:-

Titanium Alloy (Ti6A14V) -

Osseointegration - Cell culture -

Histopathology-DLC coating

\section{Abstract}

Titanium alloys (Ti6A14V) are biomaterials of choice in dentistry, due totheir resistance to the biological constraints of the environment. Their use still causes in a number of cases, problems of osseointegrationthat urge us to raise again the question of the interface of titanium alloys withmineralized tissues in particular. The purpose of this study isfirst to evaluate the biocompatibility of these implants in the biological medium while offering alternative proposals for improving the osseointegration of these implants. Two studies were first conducted for this evaluation: in vitro study on human fibroblast cell cultures and bacterial colonization in the presence of four bacterial strains (Escherichia coli, Klebsiella pneumoniae, Staphylococcus aureus, Haemolytic streptococcus) with and without implants, in vivo study on Wistar wistarrats $(\mathrm{n}=35)$ which consists in the implantation of the biomaterial at the gingival sulcus and the renal capsule ; procurement of target organs of the cytotoxicity (sulcus, kidney and liver) and their morphological study withan optical microscope. Our results showed that the implants of titanium alloy (Ti6A14V) indeed disrupt the cellular structure of the organs studied compared to controls. The proliferation of bacterial strains studied was substantially similar in culture plates with and without implants. The proliferation of human fibroblasts in cell culture showed no significant change between the implants pits and the control pits. We concluded that the implants of titanium alloy (Ti6A14V) were biocompatible in vitro but cause some problems in vivo. This could explain the negative impact of these implants on osseointegration. The surface of implantscouldbe a limiting factorfor the biocompatibility and the osseointegration of titanium alloys (Ti6A14V). We have then showed, with a similar histopathological study, that the coating of the implants of titanium

Corresponding Author:- Sidqui M.

Address:- Consultations and Dental Emergency Services, Prosthetic joint, Faculty of Dentistry, Casablanca. Hassan II University of Casablanca. Morocco. 
alloywithDiamond- Like Carbon (DLC) reduce completely the observed effects in the kidney and the liver rat.

Copy Right, IJAR, 2017,. All rights reserved.

\section{Introduction:-}

Titanium alloys (Ti6A14V) are choice biomaterials used in implant and maxillofacial surgery, given their resistance to the biological constraints of the environment. Titanium is an excellent biomaterial whose integration is done by plastic deformation of the bone -implant interface. The metal is permanently incorporated into the bone [1, 2, 3]. The success of osseointegration depends on the existence of multiple factors:biocompatibilityof the biomaterial implant-bone interface, the surface of the implant, the impact of the chemical fluids on the material, the adhesion and proliferation of bacteria in the oral cavity on the surface of the implant, and finally the prosthetic imperatives [4, $5,6,7,8,9,10,11,12]$. However, although these biomaterials are already in use, their use still causes problems in a number of cases, that is what led us to raise the question of bio-reactivity interface of titanium alloys with mineralized tissues in particular $[6,7,13]$. To improve the biocompatibility of these implants, the coating by Diamond-Like Carbon (DLC) is often suggested for its good biocompatibility in the oral cavity [14, 15]. In this research, we first reassessed the biocompatibility of titanium alloy implants (Ti6A14V) by two types of study, with an in vitro human fibroblasts culture and a colonization test with four bacterial strains, and with an in vivo study on Wistar Wistar rats by implantation of biomaterial at the level of the lower gingival sulcus and in the renal capsule. Then, in order to improve osseointegration of the titanium alloy implants (Ti6A14V), we proceeded with the coating of the titanium alloy implants by Diamond-Like Carbon (DLC) already tested biocompatible and not cytotoxic in stomatology.

\section{Materials and Methods:-}

\section{Biomaterials:-}

Implants made of titanium alloy Ti6Al4V (80\% titanium, 6\% Aluminum, 14\% vanadium) were made by using a disk placed on a mandrel carried by a hand-piece, in several samples of $2 \mathrm{~mm}$ length and $3.75 \mathrm{~mm}$ width. Implants were disinfected (by Hexanios $\mathrm{G}+\mathrm{R}$, Anios Laboratory) for 15 minutes then sterilized by moist autoclave (Tau Clave 3000 , Vacuum) $120^{\circ} \mathrm{C}$ for $30 \mathrm{~min}$.

\section{Coating technique:-}

The deposition of carbon layers has been made in the laboratory of Condensed Matter Physics of the Faculty of Sciences of Amiens, using the technique of plasma enhanced chemical vapor deposition described by Bharat Bhushan and [7]. Initially, an etching was made at apressure of 3PA,power voltage of 250W-770V, subsequently, the amorphous carbon layers were deposited using the following parameters: $1 \mathrm{~Pa}, 250 \mathrm{~W}-454 \mathrm{~V}$ for $95 \mathrm{~min}$.

\section{Cell culture:-}

The cells used are from a primary culture of human fibroblasts from a gingival biopsy performed during the extraction of a healthy 3rd lower molar imposed byorthodontic indication with the patient's consent. The culture medium used is the HAM'S whose composition is 10\% fœtalveal serum (Eurobio), 1\% L-glutamine (Eurobio), 0.5\% penicillin-streptomycin (Eurobio), 5\% of the Ultroser G (Biosepra), 0.5\% Fungizone (Sigma). Once they become confluent, the cells were trypsinized, samples of Ti6Al4V titanium implants were placed in culture plates of 12 pits, and cells were seeded at a concentration of $1 \times 10^{5}$ cells per ml. Control pits were prepared in the same conditions without implants. All cell cultures were observed daily for a week, using an optical microscope with an inverted stand (Swift Instruments International SA). The cell density was assessed by cell counting in a Malassez's cell accordingtothe exclusion principle of Trypan blue.

\section{Bacteriological study:-}

Four bacterial strains related to the oral cavity and referenced at the Pasteur Institute of Morocco were used for this study (Escherichia coli, Klebsiella pneumoniae, Staphylococcus aureus, Streptococcus $\beta$-Haemolytic). The culture medium used is the Muller Hinton agar for Escherichia coli, Klebsiella pneumoniae, Staphylococcus aureus and Muller Hinton blood for $\beta$-Hemolytic Streptococcus. Samples of Ti6Al4V titanium implants were placed on the surface of agar plates previously seeded with the four bacterial strains at a concentration of $1 \times 10^{8}$ bacteria $/ \mathrm{ml}$. The experiment was performed three times for each bacterial strain. The negative control plates were prepared in the same conditions without the implant. The total period of incubation lasted seven days. The bacterial growth was observed daily to the naked eye and with the use of a binocular magnifying glass (Olympus VMZ, Japan). 


\section{Histopathological Study:-}

The study was conducted on 25 Wistar Wistarrats, adult male and female, body weight of 250 to $350 \mathrm{~g}$, from the Centre for Research and Training of the Faculty of Medicine and Pharmacy in Casablanca. The rats were divided into 3 groups: 10 rats implanted in the sulcus, 10 rats at the left kidney capsule and 5 control rats. The animals were anesthetized intraperitoneally with a solution of $1 \mathrm{~g}$ of thiopental (Sandoz GmbH, Kundl, Austria) dissolved in 100 $\mathrm{ml}$ of $\mathrm{NaCl} 9 \%$ at 1.5 to $2 \mathrm{ml}$ of this solution. No antibiotic therapy was administered in particular. Daily for one month, the side effects: vomiting, diarrhea, hair condition have been observed and identified. Each week, the presence or absence of inflammation and gingival bleeding was noted. The sacrifice of animals was performed 30 days after implantation. Each animal was first anesthetized as described above and samples of liver, kidney and implanted para-symphyseal mucosa were performed. A macroscopic study was performed before fixation in formalin $10 \%$. The samples were embedded in paraffin and cut on a microtome $(4 \mu \mathrm{m})$. A color standard in hematein-eosin was performed and microscopic slides were observed under an optical microscope (Olympus, Japan).

Statistical study

Statistical study was performed by using Epi Info using the Chi-square test for qualitative data.

\section{Results:-}

\section{Cell culture:-}

Cells grown in the presence of titanium alloy implants showed a similar cell proliferation in all wells with or without titanium implants throughout the experimental period. Variances compared to controls were not significant ( $p$ > 0.05). The morphology and cell behavior were similar in control and experimental pits (Figures 1 and $2 \mathbf{c}$ et d).

\section{Bacteriological study:-}

The proliferation of the four bacterial strains (Escherichia coli, Klebsiella pneumoniae, Staphylococcus aureus, Streptococcus $\beta$-haemolytic) studied with different culture media chosen was similar in both culture dishes witnesses in culture dishes in the presence of implant titanium alloy (Ti6Al4V) $(p=0,057)$. However, observations of various boxes of bacterial cultures with a dissecting microscope and found that bacterial growth is important at the periphery of several boxes and decreases gradually up to the implant, with an area of reduced growth below $0.5 \mathrm{~mm}$ around the implant. In the remaining boxes, bacterial growth is normal as well as around the periphery of the implant (Figure 2).

\section{Histopathological study in animal model:-}

During the implantation period, no animal has shown the sought side effects. However, the observation of sections by optical microscope indicated some cytotoxicity in the gum and kidney and manifested by a slight enlargement of the gingival epithelial cells and kidney with low chromatin condensation in renal cell. It also reflected a stimulation of cell proliferation in vivo $(\mathrm{p}=0,0037)$. Liver cells and lobular veins and centrilobular hypertrophy are significant in comparison to the control cells $(\mathrm{p}=0,13)$ and indicated a cardiovascular failure that is induced by chronic cytotoxicity due to the implant (Figures 3). Observation of sections of the gingiva revealed no difference between control rats and implanted rats.

\section{Discussion:-}

The in vitro study in cultured human fibroblasts of the oral cavity and bacterial colonization has shown that titanium implants Ti6A14V show no cytotoxicity. However, the in vivo study shows some cytotoxicity of implants in the animal model used. This could be explained by the multiple interactions of the biological environment on the biomaterial that promote low failure rate of osseointegration implantology. Indeed, the topography of the implant promotes contact between cell components and molecular bio-guests and the surface of the implant during osseointegration $[2,16,17,18]$. According to J. Sternad $[9,10,13,19,20]$, roughness, surface chemistry and surface treatment of implants has a great impact on the bone-implant interface. Many current research focuses on changes of surface topography of implant materials to improve osseointegration [2, 3, 18]. The exact role of the surface topography of implants on the early stages of osseointegration of dental implants remains poorly understood. In addition, comparative clinical studies with different implant surfaces are rarely performed[13,20]. The originality of this study is that it is carried by two types of studies in vitro and in vivo for the first assessment biorectivity and cytotoxicity of titanium alloy implants (Ti6A14V), which pose still some problems osseointegration and then to improve osseointegration of titanium alloy implants with a coating of Diamond - Like Carbon (DLC). 
The results of cell culture and colonization of the four bacterial strains does not confirm this cytotoxicity. This prompted us to consider further studies in vitro assays of enzymes and oxidative stress factors involved. We also used to assess the fibroblasts of titanium alloys, but it might be wiser to work on osteoblasts that are involved in the mechanisms of osseointegration. The fibroblasts, however, have the advantage of being more accessible and widely distributed in all the body. Our results of in vivo studies have shown that implants made of titanium alloy (Ti6A14V) more or less disturb the cellular structure of organs studied compared to controls. We concluded that implants made of titanium alloy (Ti6A14V) are biocompatible in vitro but pose some problems biorectivity vivo. This could explain, at least in part, the impact of those implants osseointegration and mineralized tissues in particular. The surface of implants, would by most authors, the limiting factor of this biorectivity $(C, D, E)$.

To improve the osseointegration of titanium alloys (Ti6A14V), we suggest lining or coating of titanium alloy implants by Diamond - Like Carbon (DLC) already tested biocompatible and not cytotoxic in dentistry [15, 24, 25]. Indeed, in vivo evaluation of titanium alloy coated with DLC carbon in our laboratory has demonstrated the disappearance biorectivity problems described in this study [preliminary results].

We concluded that the coating of titanium alloys by the diamond-like carbon could improve osteointegration of titanium alloy implants implantology.

\section{Cells number:}

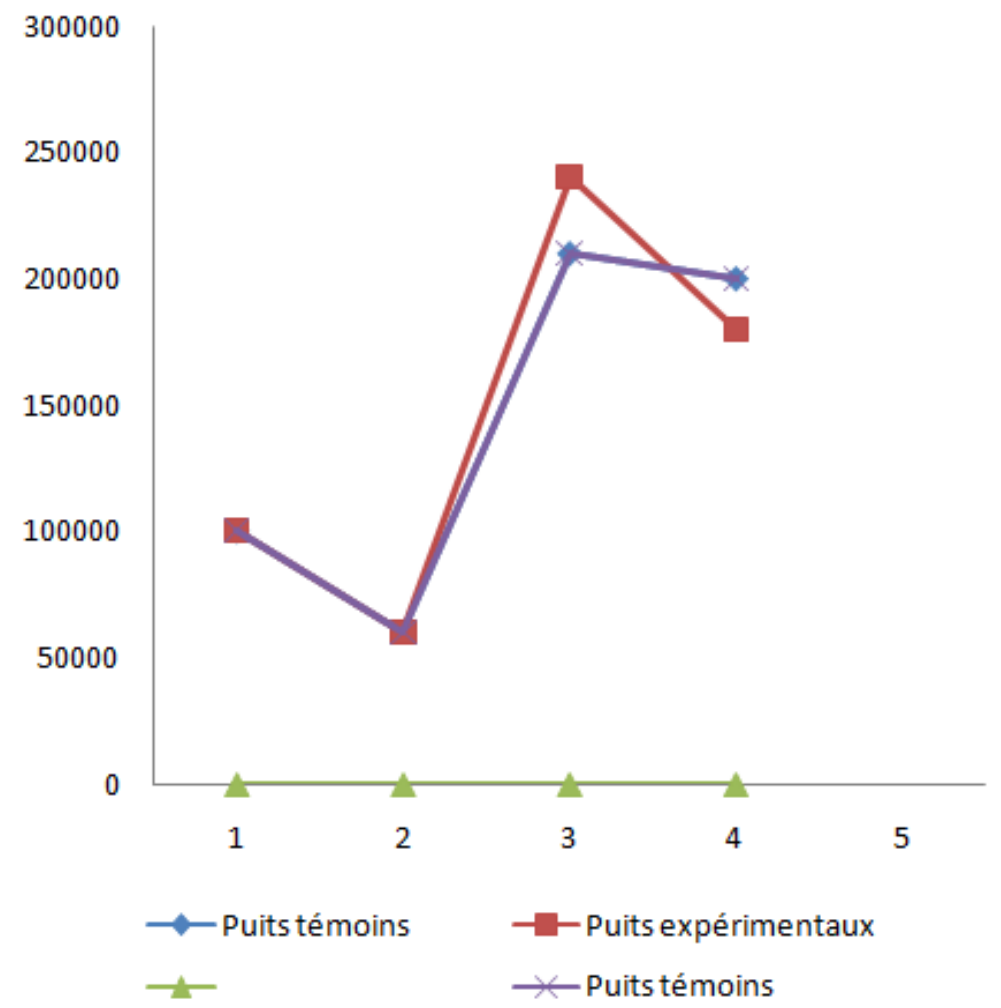

Days number

Figure 1:-Proliferation of human fibroblasts from the oral cavity over time in the presence of titanium alloy implant Ti6A14V. 

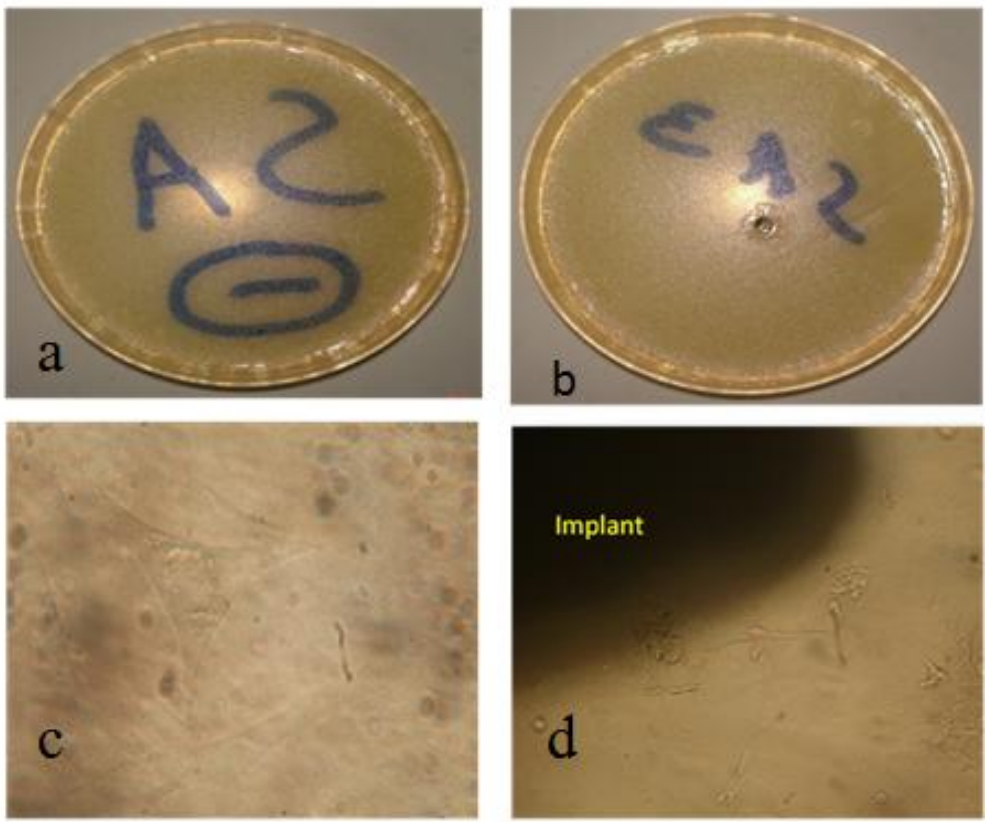

Figure 2:- in vitro study on human fibroblast cell cultures and bacterial colonization.

a) Staphylococcus aureus in the absence of titanium alloy (Ti6A14V).

b) Staphylococcus aureusin the presence of titanium alloy (Ti6A14V).

c) Shadowing inverted microscope stand of the proliferation of human fibroblasts from the oral cavity without implant.

d) Shadowing inverted microscope stand of the proliferation of human fibroblasts from the oral cavity with implant.
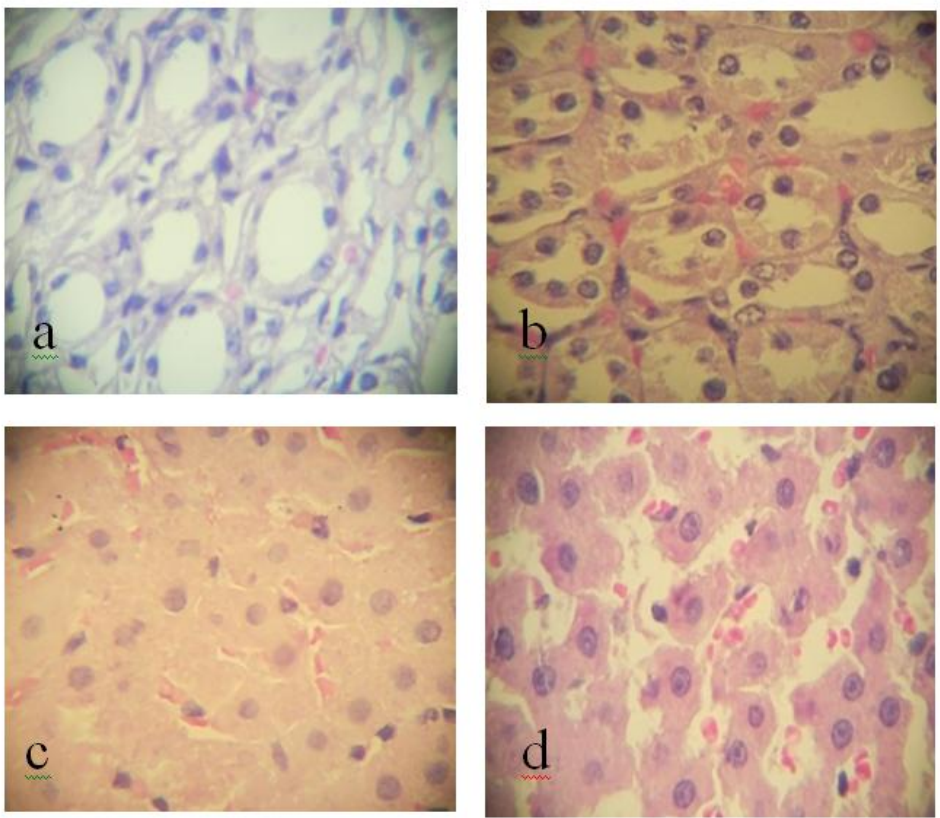

Figure 3:- Optical microscope observation of target organ cytotoxicity.

a) Optical microscope observation of Control kidney $(\mathrm{G}=400 \mathrm{x})$.

b) Optical microscope observation of Kidney implanted titanium alloy Ti6A14V $(\mathrm{G}=400 \mathrm{x})$.

c) Optical microscope observation of Liver control $(\mathrm{G}=400 \mathrm{x})$.

d) Optical microscope observation of Liverrat implanted titanium alloy Ti6A14V $(\mathrm{G}=400 \mathrm{x})$. 


\section{Bibliography:-}

1. Branemark R, Huaud J B, Bertrand M. L’Ostéointégration : un nouveau concept chirurgical dans la réhabilitation des amputés. e-mémoires de l'Académie Nationale de Chirurgie, 2006;5(4) : 36-40.

2. Friedmann.A et al. Convergent methods assessing bone growth in an experimental model at dental implants in the minipig. Annals of Anatomy 196 ;(2014): 100-107

3. Piattelli.P et coll. Histologic studies on osseointegration: Soft tissuesresponse to implant surfaces and components. A review. Dental Materials 27 ; (2011) :53-60

4. Xu B, Zhang J, Brewer E, Tu Q, Yu L, Tang J, Krebsbach P, Wieland M, Chen J. Osterix Enhances BMSC-associated Osseointegration of Implants. J Dent Res, 2009; 88(11): 1003-7.

5. Depprich R, Ommerborn M, Zipprich H, Naujoks Ch, Handsche J, Wiesmann H P, Kübler N R, Meyer U. Behavior of osteoblastic cells cultured on titanium and structured zirconia surfaces. Head\& Face Medicine, 2008;4:29-31.

6. Stadlinger B, Pilling E, Huhle M, Mai R, Bierbaum S, Scharnweber Det all. Evaluation of osseointegration of dental implants coated with collagen, chondroitin sulphate and BMP-4: an animal study Int J. Oral Maxillofac Surg, 2008; 37: 54-9.

7. Chiesa R, Giavaresi G, Fini M, Sandrini E, Giordano C, Bianchi A, Giardino R. In vitro and in vivo performance of a novel surface treatment to enhance osseointegration of endosseous implants.Oral Surg Oral Med Oral Pathol Oral RadiolEndod,2007; 103:745-56.

8. Anselme.K et al. Cell/Material Interfaces: Influence of Surface Chemistry and Surface Topography on Cell Adhesion Journal of Adhesion Science and Technology 24 ;(2010): 831-852

9. Davies.J.E et al. Topographic scale-range synergy at the functional bone/implant Interface. Biomaterials 35; (2014): 25-35.

10. Faia-Torres.A.B et al. Differential regulation of osteogenic differentiation of stem cells on surface roughness gradients. Biomaterials 35; (2014): 9023-9032

11. Hua.N.M et coll. Mechanical properties and in vitro bioactivity of injectable and self-setting calcium sulfate/nanoHA/collagen bone graft substitute. Journal of the mechanical behaviour of biomedical materials 12; (2012): 119-128

12. Wen.B et coll.Bone Tissue Engineering Around Dental Implants. Stem Cell Biology and Tissue Engineering in Dental Sciences; (2015): 749-764.

13. Seo.C.H et al. Micropit surfaces designed for accelerating osteogenic differentiation of murine mesenchymal stem cells via enhancing focal adhesion and actin polymerization. Biomaterials 35; (2014): 2245-2252

14. Kumari TV, Anil Kumar P R, Muraleedharan C V, Bhuvaneshwar G S, Sampeur Y, Derangere F, Suryanara R.In vitro cytocompatibility studies of Diamond Like Carbon coatings on titanium. Bio-Medical Materials and Engineering, 2002;12:329- 38 .

15. Nakayama T, et al. Polarization of osteoclasts on dental implant materials is similar to that observed on bone. $\mathbf{J}$ Oral Biosci (2014), http://dx.doi.org/10.1016/j.job.2014.06.005.

16. Zhou J, Pavon-Djavid G, Anagnostou F, Migonney V. Inhibition de l'adhérence de Porphyromonas gingivalis sur la surface de titane greffé de poly (styrène sulfonate de sodium).ITBM-RBM,2007; 28: 42-8.

17. Gaucher H, Bentley K, Roy S, Head T, Blomfield J, Blondeau F et al. Une étude multicentrique sur les implants Osseotite comme support aux prothèses mandibulaires: rapport après 3 ans. J Can Dent Assoc, 2001; 67(9):528-33.

18. Comăneanu.R.M et al.Correlations between cyto-histopathological tissue changes at the dental implant interface and the degree of surface processing. Rom J Morphol Embryol 2014 ; 55(2):335-34

19. 19.Prodanov.L et al. The effect of nanometric surface texture on bone contact to titanium implants in rabbit tibia. Biomaterials 34; (2013): 2920-2927

20. Shibata.Y et coll. A review of improved fixation methods for dental implants. Part I: surface optimization for rapid osseointegration. Journal of prosthodontic Research 59; 2015: 20-33

21. Birmingham.E et al. Osteogenic differenciation of mesenchymal stem cells is regulated by osteocyte and osteoblast cells in a simplified bone niche.Osteogenesis of MSCs in a simplified bone niche. European Cells and Materials Vol.23 ; 2012 :13-27.

22. Boccafoschi.F, Mosca.C, Ramella.M, Valente.G \& Cannas.M (2013) The effect of mechanical strain on soft (cardiovascular) and hard (bone) tissues, Cell Adhesion \& Migration, 7:2, 165-173, DOI: 10.4161/cam.23020

23. Bohner.M et al .Calcium phosphate bone graft substitutes: Failures and hopes. Journal of the European Ceramic Society 32; (2012): 2663-2671

24. Alanazi A, Nojiri C, Noguchi T, Kido T, Komatsu K K,Funakubo A. Improved blood compatibility of DLC coated polymeric materials. ASAIO J, $1999 ; 45$.

25. Alanazi A, Nojiri C, Kido T, Noguchi T, Ohgoe Y, Matsuda T et al. Engineering analysis of Diamond - Like Carbone caoted polymeric materials for biomedical applications. Artificial Organs,2000; 24(8): 624-627. 